\title{
Effect of intratumoral abscess/necrosis on the outcome for head and neck cancer patients treated by hypofractionated stereotactic re-irradiation using CyberKnife ${ }^{\circledR}$
}

\author{
HIDEYA YAMAZAKI $^{1,2}$, MIKIO OGITA $^{3}$, KENGO HIMEI ${ }^{4}$, SATOAKI NAKAMURA $^{1}$, \\ GEN SUZUKI $^{1}$, TADAYUKI KOTSUMA $^{5}$, KEN YOSHIDA $^{5}$ and YASUO YOSHIOKA ${ }^{6}$
}

\begin{abstract}
${ }^{1}$ Department of Radiology, Graduate School of Medical Science, Kyoto Prefectural University of Medicine, Kyoto 602-8566; ${ }^{2}$ CyberKnife Center, Soseikai General Hospital, Kyoto 612-8473; ${ }^{3}$ Radiotherapy Department, Fujimoto Hayasuzu Hospital, Miyakonojo, Miyazaki 885-0055; ${ }^{4}$ Department of Radiology, Japanese Red Cross Okayama Hospital, Okayama 700-8607;

${ }^{5}$ Department of Radiation Oncology, National Hospital Organization Osaka National Hospital, Osaka 540-0006;

${ }^{6}$ Department of Radiation Oncology, Osaka University Graduate School of Medicine, Suita, Osaka 565-0871, Japan
\end{abstract}

Received January 5, 2016; Accepted July 22, 2017

DOI: $10.3892 / \mathrm{mco} .2017 .1339$

\begin{abstract}
The aim of the present study was to elucidate the effect of intratumoral abscess/necrosis (AN) on the outcome of patients with recurrent head and neck cancer (HNC) treated by stereotactic radiotherapy. The records of 67 patients treated with CyberKnife ${ }^{\circledR}$ in four institutes between August 2000 and July 2010 were reviewed. The frequency of AN appeared to be increased in younger postoperative patients with large ulcerative tumors. The $\mathrm{AN}^{+}$group exhibited a better initial response rate compared with the $\mathrm{AN}^{-}$group (64 vs. 33\%, respectively; $\mathrm{P}=0.04)$. The 1-year local control rate was 51 and $75 \%$ in the $\mathrm{AN}^{+}$and $\mathrm{AN}^{-}$groups, respectively $(\mathrm{P}=0.01)$, while the respective 1-year overall survival rates were 53 and and $71 \%$ $(\mathrm{P}=0.0004)$. A total of 21 patients $(31 \%)$ experienced grade $\geq 3$ toxicities, and carotid blowout syndrome (CBOS) was found in 11 patients, resulting in 8 deaths. A significantly larger proportion of patients in the $\mathrm{AN}^{+}$group developed CBOS $(8 / 18 ; 44 \%)$ compared with the $\mathrm{AN}^{-}$group $(3 / 49 ; 6 \%)(\mathrm{P}=0.001)$. Therefore, AN may be an important prognostic factor for patients with recurrent $\mathrm{HNC}$, as well as a predictor of lethal toxicity due to CBOS.
\end{abstract}

\section{Introduction}

The treatment of unresectable head and neck cancer (HNC) has improved with the use of modern chemotherapy and radio-

Correspondence to: Dr Hideya Yamazaki, Department of Radiology, Graduate School of Medical Science, Kyoto Prefectural University of Medicine, 465 Kajiicho Kawaramachi Hirokoji, Kamigyo-ku, Kyoto 602-8566, Japan

E-mail: hideya10@hotmail.com

Key words: head neck cancer, reirradiation, stereotactic radiotherapy, carotid blowout syndrome, CyberKnife, abscess necrosis therapy $(1,2)$. However, locoregional failure remains a major concern, preventing complete cure. Although salvage surgery has the highest disease-eradicating potential, only one-third of patients are eligible (3). After surgery, chemotherapy is a frequently preferred option; however, the resulting median survival time is $<9$ months (4). With the advancement of modern radiation techniques, re-irradiation using advanced technologies, including intensity-modulated radiation therapy and/or stereotactic radiotherapy, has become a promising therapeutic option. The image-guided stereotactic radiotherapy system CyberKnife ${ }^{\circledR}$ enables precise dose delivery over short treatment periods (5-9). Several institutions, including ours, have reported on the outcome and toxicity of re-irradiation using CyberKnife ${ }^{\circledR}$ hypofractionated stereotactic body radiation therapy (SBRT) (5-10).

Lethal carotid blowout syndrome (CBOS) was previously investigated in patients with $\operatorname{HNC}(7,9)$, and the findings prompted the subsequent investigation of predisposing factors for CBOS (10). The presence of ulceration and lymph node irradiation were found to be risk factors for CBOS, and the CBOS index, including carotid invasion of $>180^{\circ}$, was found to be useful for risk factor classification and determination of indications for re-irradiation (10). As an increased frequency of AN was observed among CBOS cases in an initial single-institution study by our group (7), an assessment of multi-institutional records of patients with HNC was conducted, focusing on AN. The aim of the present study was to investigate the role of $\mathrm{AN}$ in tumor control and toxicity following re-irradiation using CyberKnife ${ }^{\circledR}$ SBRT in HNC patients.

\section{Patients and methods}

Patients. The medical records of patients who underwent CyberKnife ${ }^{\circledR}$ SBRT (Accuray; Sunnyvale, CA, USA) in four hospitals [Soseikai General Hospital (Kyoto, Japan), Osaka University Hospital (Osaka, Japan), Fujimoto Hayasuzu Hospital (Miyakonojo, Japan) and Okayama Kyokuto Hospital 
Table I. Characteristics and treatment factors of patients.

\begin{tabular}{|c|c|c|c|c|c|}
\hline \multirow[b]{2}{*}{ Variables } & \multicolumn{2}{|c|}{$\begin{array}{c}\text { Abscess/necrosis (-) } \\
\qquad(\mathrm{n}=49)\end{array}$} & \multicolumn{2}{|c|}{$\begin{array}{l}\text { Abscess/necrosis }(+) \\
\qquad(\mathrm{n}=18)\end{array}$} & \multirow[b]{2}{*}{ P-value } \\
\hline & $\begin{array}{l}\text { No. of patients } \\
\text { or median (range) }\end{array}$ & $(\%)$ & $\begin{array}{l}\text { No. of patients } \\
\text { or median (range) }\end{array}$ & $(\%)$ & \\
\hline Age (years) & $63(45-83)$ & & $60(44-66)$ & & 0.008 \\
\hline \multicolumn{6}{|l|}{ Gender } \\
\hline Female & 11 & $(22)$ & 4 & $(22)$ & 0.690 \\
\hline Male & 38 & $(78)$ & 14 & (78) & \\
\hline \multicolumn{6}{|l|}{ Disease } \\
\hline Nasopharyngeal cancer & 32 & $(65)$ & 7 & (39) & 0.070 \\
\hline Oropharyngeal cancer & 9 & $(18)$ & 8 & $(44)$ & \\
\hline Hypopharyngeal cancer & 8 & $(16)$ & 2 & (11) & \\
\hline Oral cancer & 0 & $(0)$ & 1 & (6) & \\
\hline \multicolumn{6}{|l|}{ Irradiated area } \\
\hline Primary site & 39 & $(80)$ & 11 & (61) & 0.110 \\
\hline Lymph node & 10 & $(20)$ & 7 & (39) & \\
\hline Lymph node alone & 4 & $(40)$ & 2 & (29) & \\
\hline Primary and lymph node & 6 & $(60)$ & 5 & $(71)$ & \\
\hline \multicolumn{6}{|l|}{ Ulceration } \\
\hline No & 41 & $(84)$ & 9 & $(50)$ & 0.006 \\
\hline Yes & 8 & $(16)$ & 9 & $(50)$ & \\
\hline \multicolumn{6}{|l|}{ Surgical history } \\
\hline No & 36 & $(73)$ & 8 & $(44)$ & 0.02 \\
\hline Yes & 13 & $(27)$ & 10 & $(56)$ & \\
\hline Planning target volume $\left(\mathrm{cm}^{3}\right)$ & $13.5(1-339)$ & & $53(5.2-241)$ & & 0.003 \\
\hline Treatment interval (months) & $17.6(3.1-122)$ & & $24(8.3-86.2)$ & & 0.770 \\
\hline Response $^{\mathrm{a}}$ & $15 / 16$ & $(64)$ & $3 / 3$ & (33) & 0.040 \\
\hline
\end{tabular}

${ }^{a}$ Complete/partial response. Bold print indicates statistical significance.

(Okayama, Japan)] between August 2000 and July 2010 were reviewed for inclusion in the present study. Among the patients with HNC who received re-irradiation up to the prescribed dose for residual or recurrent tumors within the irradiated area, only those who satisfied the following criteria were included: Patients who had undergone imaging analysis prior to SBRT to confirm the presence or absence of $\mathrm{AN}$ and had completed a course of radical treatment, including previous radiotherapy at $\geq 40$ Gy [biological equivalent 2-Gy fractions (EQD2) described in detail below], with or without chemotherapy and surgery. Previous radiotherapy consisted of 40-74.8 Gy/20-62 fractions (1.2-2 Gy fractionation), with estimated EQD2 of 40-75.1 Gy $(\alpha / \beta=10)$.

A total of 67 patients were considered eligible for assessment. The patient characteristics are listed in Table I nd a representative case of a patient with intratumoral $\mathrm{AN}$ is presented in Fig. 1. The conventional technique using a linear accelerator was used during the first course of radiotherapy. SBRT re-irradiation was performed using the CyberKnife ${ }^{\circledR}$ system. The patients received a median dose of $30 \mathrm{~Gy}$ (range, 15-39 Gy) over a median of five daily fractions (range,

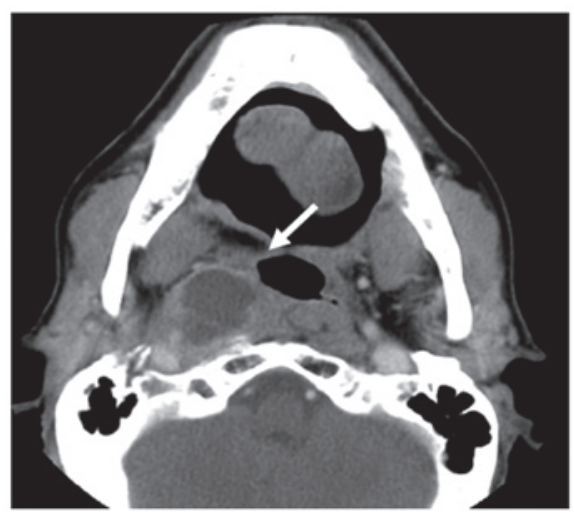

Figure 1. Presentation of a case with intratumoral abscess/necrosis. A 61-year-old man with oropharyngeal cancer (right lateral wall) underwent preoperative radiotherapy at $40 \mathrm{~Gy}$ in 20 fractions with intra-arterial chemotherapy (cisplatin) followed by surgery (primary cancer and right neck dissection) and was pathologically classified as T3NO. A recurrent tumor was detected at the primary site with subsequent extension to the Rouvière node 4 months later. The patient then received CyberKnife ${ }^{\circledR}$ hypofractionated stereotactic radiation therapy with $37 \mathrm{~Gy}$ administered in 10 fractions. The patient exhibited an intratumoral abscess/necrosis (arrow) with ulceration with a planning target volume of $132 \mathrm{~cm}^{3}$. One month after treatment, the patient developed carotid blowout syndrome and succumbed within 1 day. 
Table II. Analysis of prognostic factors.

\begin{tabular}{|c|c|c|c|c|c|c|}
\hline Variables & No. of patients & $1-y \operatorname{LC}(\%)$ & P-value & MST (months) & $1-y$ OS (\%) & P-value \\
\hline \multicolumn{7}{|c|}{ Age (years) } \\
\hline$<70$ & 53 & 67 & \multirow[t]{2}{*}{0.46} & 19.4 & 69 & \multirow[t]{2}{*}{0.670} \\
\hline$\geq 70$ & 14 & 73 & & 20.8 & 53 & \\
\hline \multicolumn{7}{|l|}{ Sex } \\
\hline Male & 52 & 70 & \multirow[t]{2}{*}{0.89} & 17.8 & 67 & \multirow[t]{2}{*}{0.280} \\
\hline Female & 15 & 64 & & 48 & 62 & \\
\hline \multicolumn{7}{|c|}{ PTV $\left(\mathrm{cm}^{3}\right)$} \\
\hline$\leq 40$ & 44 & 70 & \multirow[t]{2}{*}{0.54} & 24.9 & 76 & \multirow[t]{2}{*}{0.020} \\
\hline$>40$ & 23 & 66 & & 10.3 & 47 & \\
\hline \multicolumn{7}{|c|}{ Abscess/necrosis (AN) } \\
\hline Yes & 18 & 51 & \multirow{2}{*}{0.01} & 13.9 & 53 & \multirow[t]{2}{*}{$<0.001$} \\
\hline No & 49 & 75 & & 28.2 & 71 & \\
\hline \multicolumn{7}{|c|}{ Ulceration } \\
\hline Yes & 17 & 55 & \multirow[t]{2}{*}{0.05} & 6.6 & 38 & \multirow[t]{2}{*}{$<0.001$} \\
\hline No & 50 & 74 & & 27.5 & 76 & \\
\hline \multicolumn{7}{|c|}{ Primary cancer type } \\
\hline NPC & 39 & 77 & \multirow[t]{2}{*}{0.06} & 42.3 & 75 & \multirow[t]{2}{*}{$<0.001$} \\
\hline Others & 28 & 54 & & 13.9 & 53 & \\
\hline \multicolumn{7}{|c|}{ Treatment interval ${ }^{\mathrm{a}}$ (months) } \\
\hline$\leq 30$ & 38 & 56 & \multirow[t]{2}{*}{0.05} & 17.7 & 61 & \multirow[t]{2}{*}{0.150} \\
\hline$>30$ & 29 & 82 & & 39.9 & 72 & \\
\hline \multicolumn{7}{|c|}{ Prescribed dose (EQD2), Gy } \\
\hline$\leq 40$ & 34 & 60 & \multirow[t]{2}{*}{0.14} & 14.8 & 60 & \multirow[t]{2}{*}{0.010} \\
\hline$>40$ & 33 & 76 & & 42.3 & 72 & \\
\hline \multicolumn{7}{|c|}{ Surgical history } \\
\hline Yes & 23 & 67 & \multirow[t]{2}{*}{0.59} & 14.4 & 65 & \multirow[t]{2}{*}{0.500} \\
\hline No & 44 & 69 & & 24.8 & 66 & \\
\hline
\end{tabular}

${ }^{\mathrm{a}}$ Interval between CyberKnife ${ }^{\circledR}$ stereotactic body radiation therapy and prior radiation therapy. Bold print indicates statistical significance. 1-y LC, one-year local control; MST, median survival time; OS, overall survival; NPC, nasopharygeal cancer; EQD2, biologically effective dose in 2-Gy fractions; PTV, planning target volume.
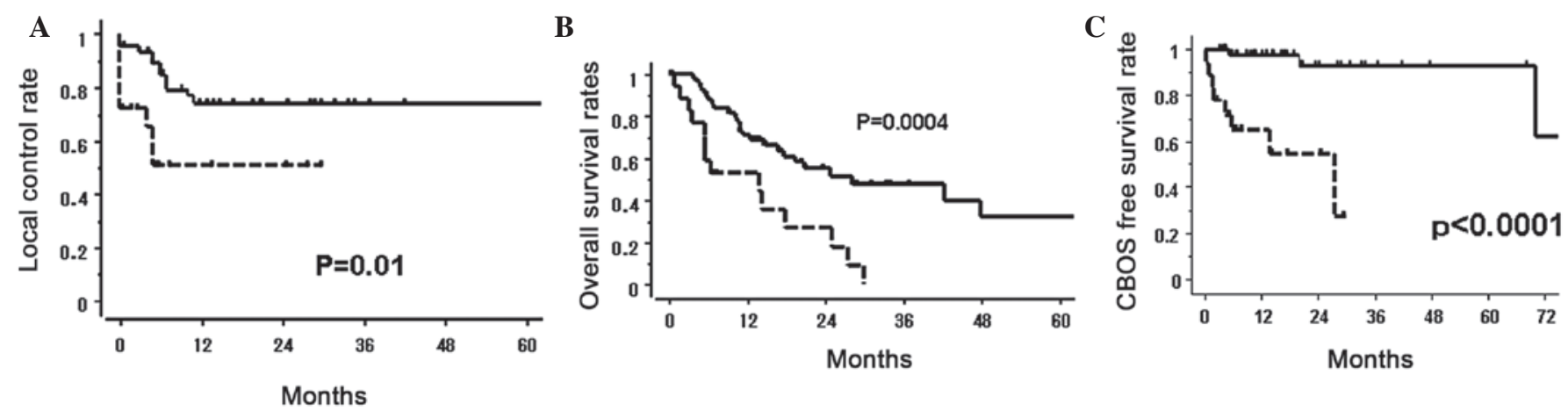

Figure 2. Effect of intratumoral AN on the outcome for patients with head and neck cancer. Solid line, $\mathrm{AN}^{-}$cases; broken line, $\mathrm{AN}^{+}$cases. (A) Local control rate, $(\mathrm{B})$ overall survival rate and $(\mathrm{C}) \mathrm{CBOS}$-free survival rate depending on the presence of AN. AN, abscess/necrosis; CBOS, carotid blowout syndrome.

1-8 fractions) that were prescribed at D90, D95, or a marginal dose. D90 (D95) was defined as a minimum dose covering $90 \%(95 \%)$ of the planning target volume (PTV). The marginal dose prescription was defined as the percentage (maximum dose, 100\%) of the isodose curve covering the PTV. None of the patients received chemotherapy. All irradiated lesions were located inside areas previously subjected to high-dose irradiation. Prior to SBRT, the presence of AN was confirmed 
by imaging analysis, such as computed tomography (CT) and/or magnetic resonance imaging (MRI), contrast-enhanced if required. AN was identified as a focal area of low density with a surrounding rim of high density and/or enhancement on CT, or a focal area of high signal intensity on T2-weighted images, or a focal area of low signal intensity on T1-weighted images with a surrounding rim of enhancement on MRI (11). These interpretations were made by at least one diagnostic radiologist and one radiation oncologist. The presence of mucosal ulceration of the upper aerodigestive tract was determined by visual inspection (fibroscopy if required) and/or imaging analysis (CT and/or MRI). EQD2 was calculated using the linear quadratic model as follows: EQD2=prescription dose $\mathrm{x}(\alpha / \beta+$ dose per fraction $) /(\alpha / \beta+2)$, where $\alpha / \beta=10$ for tumors and 3 for organs at risk. In principle, follow-up by physical examination was performed at intervals of at least 1 month for the first year and at intervals of 3-6 months thereafter. Examination with imaging methods, such as CT and/or MRI and/or ultrasonography, was performed after 3 and 6 months, $1,1.5$ and 2 years, and at 1-year intervals thereafter, or when local or lymph node recurrence was suspected. Initial response was assessed using the Response Evaluation Criteria in Solid Tumors version 4.0 (http://www.jcog.jp/doctor/tool/ctcaev4. html). Written informed consent was obtained from the patients for the publication of their data and accompanying images.

Statistical analysis. All statistical analyses were performed using Statview 5.0 statistical software (SAS Institute, Inc., Cary, NC, USA). The percentage values were analyzed using the $\chi^{2}$ test, and values were compared using Mann-Whitney U test. Cumulative incidences were estimated by the Kaplan-Meier method. The durations were calculated from the first day of CyberKnife ${ }^{\circledR}$ SBRT. Variables that had P-values $<0.05$ were further tested by multivariate analysis using a Cox proportional hazards model. The cut-off value was set at the average or median value of each variable if not otherwise stated. All analyses used a significance level of $\mathrm{P}<0.05$.

\section{Results}

AN is associated with poor prognosis of patients with recurrent HNC following SBRT. The median follow-up time for the surviving patients after SBRT was 17 months (range, 1-122 months). As shown in Table I, the frequency of AN was significantly increased in patients who received surgery, and those who had large, ulcerative tumors; furthermore, the median age in the $\mathrm{AN}^{+}$group was significantly lower compared with that in the $\mathrm{AN}^{-}$group. Thus, younger, postoperative patients with large ulcerative tumors tended to exhibit AN. In particular, AN exhibited a strong correlation with ulceration $(\mathrm{P}=0.001$; Table $\mathrm{I})$. The $\mathrm{AN}^{-}$group exhibited a better initial response rate (15 complete responses +16 partial responses $=64 \%$ ) compared with the $\mathrm{AN}^{+}$group (3 complete responses +3 partial responses $=33 \%)(\mathrm{P}=0.04)$. The local control (LC) rate in the $\mathrm{AN}^{+}$group was $51 \%$, which was significantly lower compared with that in the $\mathrm{AN}^{-}$group (75\%; $\mathrm{P}=0.01$ ). The median survival time and 1-year survival rates for the $\mathrm{AN}^{+}$and $\mathrm{AN}^{-}$groups were 13.6 vs. 28.2 months $(\mathrm{P}<0.001)$ and 53 vs. $71 \%(\mathrm{P}=0.0004)$, respectively (Table II
Table III. Risk factors for CBOS.

\begin{tabular}{lccc}
\hline Factors & No CBOS & CBOS & $\%{ }^{\mathrm{a}}$ \\
\hline $\begin{array}{l}\text { Carotid invasion } \leq 180^{\circ} \\
\mathrm{AN}^{-}\end{array}$ & 20 & - & $(0)$ \\
$\mathrm{AN}^{+}$ & 1 & 1 & $(50)$ \\
Carotid invasion $>180^{\circ}$ & & & \\
$\mathrm{AN}^{-}$ & 26 & 3 & $(10)$ \\
$\mathrm{AN}^{+}$ & 9 & 7 & $(44)$ \\
\hline
\end{tabular}

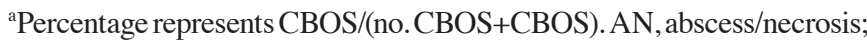
CBOS, carotid blowout syndrome.

and Fig. 2). PTV, ulceration, primary site (nasopharynx or other) and prescribed dose were statistically significant predisposing factors for reduced overall survival (OS) according to the univariate analysis (Table II). There were statistically significant differences in LC and OS rates between the $\mathrm{AN}^{+}$ and $\mathrm{AN}^{-}$groups (Table II, Fig. 2), indicating poor prognosis for patients with AN.

Toxicity. A total of 21 patients $(31 \%)$ experienced grade $\geq 3$ adverse effects. Among them, CBOS was found in 11 patients and resulted in 8 deaths, whereas the 3 remaining patients recovered following intervention. All fatal adverse effects were due to CBOS. A total of $44 \%(8 / 18)$ of patients in the $\mathrm{AN}^{+}$group and 6\% (3/49) of patients in the $\mathrm{AN}^{-}$group developed CBOS $(\mathrm{P}=0.001)$. The $\mathrm{AN}^{+}$group exhibited a lower CBOS-free survival ratio (65\% at 1 year) compared with the $\mathrm{AN}^{-}$group (98\% at 1 year; $\mathrm{P}<0.0001$; Fig. 2C). In addition, among patients with carotid invasion at $\leq 180^{\circ}$, only $\mathrm{AN}^{+}$recurrent oral cancer patients exhibited $\mathrm{CBOS}$, whereas among patients with carotid invasion at $>180^{\circ}, 44 \%$ of $\mathrm{AN}^{+}$and $10 \%$ of $\mathrm{AN}^{-}$patients developed CBOS $(\mathrm{P}<0.01$; Table III). Other grade $\geq 3$ radiation-induced adverse effects included 2 cases of mucositis requiring percutaneous endoscopic gastrostomy, 2 cases of lateral lobe necrosis (grade 4 in 1 case), 5 cases of fistulas and 1 case each of bone necrosis, soft tissue necrosis, visual disturbance and ulceration.

\section{Discussion}

To the best of our knowledge, the present study was the first to investigate $\mathrm{AN}$ as a prognostic factor in patients with recurrent HNC following re-irradiation using SBRT. Low-density areas on $\mathrm{CT}$ and/or water intensity areas on MRI, which may indicate central necrosis in the lymph node and/or ring enhancement in contrast-enhanced images $(10,11)$, are occasionally encountered in a routine clinical examination. However, it remains elusive whether these findings affect the outcome and/or adverse effects of SBRT in patients with recurrent HNC. The presence of AN has been identified as a factor associated with the inflammatory and/or infection process, which weakens the arterial walls and may result in CBOS. In addition, a hypoxic tumor environment indicates a radioresistant and infiltrative nature, which may be associated with worse prognosis. Certain studies have indicated that central necrosis in lymph nodes is indicative of malignancy 
and poor prognosis with extracapsularextension(12,13).However, patients with human papilloma virus infection have been found to have a better prognosis compared with patients without this infection, and their lymph node metastases frequently display cystic changes (14). In the present study, the detailed morphology of AN, such as wall thickness and smoothness, could not be assessed due to the heterogeneous methods of image collection (CT and MRI, with or without contrast enhancement, with the use of different image acquisition techniques and conditions); however, image interpretation for diagnostic purposes should be performed in future studies and the results of the present study should be interpretated with caution.

Patients with fatal CBOS who exhibited AN were encountered in our previous study (7). CBOS is one of the most devastating complications of HNC and mainly occurs fas a postoperative complication, particularly in patients with a history of radiotherapy and/or when the tumor compromises the vascular axis (7-10,15-17). McDonald et al (16) have reported that CBOS following re-irradiation is a rare [41/1,554 (2.6\%)] and often fatal $(75 \%)$ event. Zoumalan et al (12) reported that 15 of 33 treatment-related deaths $(40 \%)$ were associated with CBOS in a cohort of 166 patients (overall mortality rate, $9 \%$ ). Similarly, we also previously reported that CBOS occurred in $8.4 \%$ of cases among 381 HNC patients treated with 484 re-irradiation sessions at seven Japanese CyberKnife ${ }^{\circledR}$ institutions, and $69 \%$ of the cases were fatal (10). In addition, the presence of ulceration in association with carotid invasion at $>180^{\circ}$ was an important risk factor for CBOS (11). The present study identified $\mathrm{AN}$ as an additional risk factor for CBOS in patients with recurrent HNC after SBRT.

The present study had several limitations. Due to the retrospective nature of the study and inclusion of only a small number of patients with a short follow-up period, selectionand physician-based biases may exist. Therefore, the results of the present study should be confirmed in a prospective trial with a larger number of patients with longer follow-up periods. In addition, there were several confounding factors exhibiting a correlation with $\mathrm{AN}$, such as age, postoperative status, tumor volume and ulceration. Therefore, although AN was not found to be an independent risk factor, it should be taken into consideration when determining a patient's eligibility for re-irradiation using SBRT.

In conclusion, younger postoperative patients with large and ulcerative tumors tended to exhibit AN. Thus, AN is an important prognostic factor for HNC patients following reirradiation using CyberKnife ${ }^{\circledR}$, as well as a predictor of fatal CBOS.

\section{References}

1. Mazeron R, Tao Y, Lusinchi A and Bourhis J: Current concepts of management in radiotherapy for head and neck squamous-cell cancer. Oral Oncol 45: 402-408, 2009.
2. Vokes EE, Weichselbaum RR, Lippman SM and Hong WK: Head and neck cancer. N Eng J Med 328: 184-194, 1993.

3. Temam S, Pape E, Janot F, Wibault P, Julieron M, Lusinchi A, Mamelle G, Marandas P, Luboinski B and Bourhis J: Salvage surgery after failure of very accelerated radiotherapy in advanced head-and-neck squamous cell carcinoma. Int J Radiat Oncol Biol Phys 62: 1078-1083, 2005.

4. Wong SJ, Machtay M and Li Y: Locally recurrent, previously irradiated head and neck cancer: Concurrent re-irradiation and chemotherapy, or chemotherapy alone? J Clin Oncol 24: 2653-2658, 2006.

5. Lartigau EF, Tresch E, Thariat J, Graff P, Coche-Dequeant B, Benezery K, Schiappacasse L, Degardin M, Bondiau PY, Peiffert D, et al: Multi institutional phase II study of concomitant stereotactic reirradiation and cetuximab for recurrent head and neck cancer. Radiother Oncol 109: 281-285, 2013.

6. Kress MA, Sen N, Unger KR, Lominska CE, Deeken JF, Davidson BJ, Newkirk KA, Hwang J and Harter KW: Safety and efficacy of hypofractionated stereotactic body reirradiation in head and neck cancer: Long-term follow-up of a large series. Head Neck 37: 1403-1409, 2015.

7. Kodani N, Yamazaki H, Tsubokura T, Shiomi H, Kobayashi K, Nishimura T, Aibe N, Ikeno H and Nishimura T: Stereotactic body radiation therapy for head and neck tumor: Disease control and morbidity outcomes. J Radiat Res 52: 24-31, 2011.

8. Cengiz M, Özyiğit G, Yazici G, Doğan A, Yildiz F, Zorlu F, Gürkaynak M, Gullu IH, Hosal S and Akyol F: Salvage reirradiaton with stereotactic body radiotherapy for locally recurrent head-and-neck tumors. Int J Radiat Oncol Biol Phys 81: 104-109, 2011.

9. Yamazaki H, Ogita M, Kodani N, Nakamura S, Inoue H, Himei K, Kotsuma T, Yoshida K, Yoshioka Y, Yamashita K and Udono H: Frequency, outcome and prognostic factors of carotid blowout syndrome after hypofractionated re-irradiation of head and neck cancer using CyberKnife ${ }^{\circledR}$ : A multi-institutional study. Radiother Oncol 107: 305-309, 2013.

10. Yamazaki H, Ogita M, Himei K, Nakamura S, Kotsuma T, Yoshida K and Yoshioka Y: Carotid blowout syndrome in pharyngeal cancer patients treated by hypofractionated stereotactic re-irradiation using CyberKnife ${ }^{\oplus}$ : A multi-institutional matched-cohort analysis. Radiother Oncol 115: 67-71, 2015.

11. King AD, Tse GM, Ahuja AT, Yuen EH, Vlantis AC, To EW and van Hasselt AC: Necrosis in metastatic neck nodes: Diagnostic accuracy of CT, MR imaging, and US. Radiology 230: 720-726, 2004.

12. Zoumalan RA, Kleinberger AJ, Morris LG, Ranade A, Yee H, DeLacure MD and Myssiorek D: Lymph node central necrosis on computed tomography as predictor of extracapsular spread in metastatic head and neck squamous cell carcinoma: Pilot study. J Laryngol Otol 124: 1284-1288, 2010.

13. Ding ZX, Liang BL, Shen J, Xie BK, Huang SQ and Zhang B: Magnetic resonance imaging diagnosis of cervical lymph node metastasis from lingual squamous cell carcinoma. Chin J Cancer 24: 199-203, 2005 (In Chinese).

14. Goldenberg D, Begum S, Westra WH, Khan Z, Sciubba J, Pai SI, Califano JA, Tufano RP and Koch WM: Cystic lymph node metastasis in patients with head and neck cancer: An HPV-associated phenomenon. Head Neck 30: 898-903, 2008.

15. Esteller E, León X, de Juan M and Quer M: Delayed carotid blow-out syndrome: A new complication of chemoradiotherapy treatment in pharyngolaryngeal carcinoma. J Laryngol Otol 126: 1189-1191, 2012

16. McDonald MW, Moore MG and Johnstone PA: Risk of carotid blowout after reirradiation of the head and neck: A systematic review. Int J Radiat Oncol Biol Phys 82: 1083-1089, 2012.

17. Chen KC, Yen TT, Hsieh YL, Chen HC, Jiang RS, Chen WH and Liang KL: Postirradiated carotid blowout syndrome in patients with nasopharyngeal carcinoma: A case-control study. Head Neck 37: 794-799, 2015. 